Response of 85 Worm-infested Children to Treatment With Mebendazole

\begin{tabular}{l|c|c|c|c}
\hline Helminth & $\begin{array}{c}\text { No. with } \\
\text { Single } \\
\text { Infestation }\end{array}$ & $\begin{array}{c}\text { No. (\%) } \\
\text { Cured }\end{array}$ & $\begin{array}{c}\text { Total Treated } \\
\text { for any } \\
\text { Infestation* }\end{array}$ & $\begin{array}{c}\text { Total (\%) } \\
\text { Cured }\end{array}$ \\
\hline Ascaris & 9 & $9(100)$ & 19 & $19(100)$ \\
Trichuris & 23 & $21(91)$ & 33 & $31(94)$ \\
Hookworm & 17 & $16(94)$ & 33 & $27(82)$ \\
Hymmenolepis & 16 & $8(50)$ & 23 & $9(39)$ \\
\hline
\end{tabular}

*Includes children with multiple infestations (see text)

Twenty-five single infestations with Giardia lamblia cysts were treated and $10(40 \%)$ were cured. A further 13 children who also harboured worms were treated and four responded, and thus the overall cure rate was $37 \%$.

The survey yielded no evidence of drug toxicity or intolerancediarrhoea, nausea, anorexia-on direct questioning. We were unable to do blood or biochemical studies on the children but there was nothing in the literature to suggest that such tests would have been justified.

\section{Discussion}

Our results seem highly promising and generally agree with those of other studies. ${ }^{4}$ The whipworm (trichuris) is notoriously intractable and, moreover, may spread in hospitals for the mentally subnormal in Britain. ${ }^{7}$ A cure rate of $94 \%$ by a drug with such low (? absent) toxicity would enable such units to be freed effectively of not only trichuris but also Enterobius vermicularis at a single stroke. Our cure rate for trichuris infestation of $94 \%$ after three days' treatment with mebendazole compares favourably with that of $81-88 \%$ found after five or 10 days' treatment with difetarsone. 7 Strict comparison between these studies is not valid, however, as the methods for detecting parasites were different, Lynch et al. ${ }^{7}$ being able to do a much more thorough faecal examination than we found possible. Eradication of hookworm infestations $(82 \%)$ was also an important result as many children suffer because of hookworms. Our results suggest that giardia carriage may be influenced by mebendazole. In Brazil, however, Souzaet al. ${ }^{1}$ were unable to show any effect on this parasite, but their findings may have been biased by reinfestation due to a heavy load of the parasite in the environment and poor hygienic conditions. Clearly, our findings require confirmation, for though mebendazole would not be the drug of choice for treating infestation due to giardia alone (metronidazole would be better) it would be an advantage to know that deworming with mebendazole might incidentally eradicate $G$. lamblia.

While in the U.K. we neither have nor expect to have a worm problem such as exists in some parts of the world we can agree with Peña Chavarria et al., ${ }^{4}$ who treated Costa Rican patients with mebendazole in considering the drug "as a public health tool in mass therapy for helminth control." Certainly, mebendazole should prove useful in Britain for treating people with multiple infestations.

We are grateful to Janssen Pharmaceuticals Ltd. for supplying mebendazole and for financial assistance. We are also very grateful for all the help given by the school nursing staff at Canterbury House school clinic.

\footnotetext{
References

1 Souza, D. W. C., de., Lemos Souza, S. de., Neves, J., Revista Do Instituto de Medicina Tropical de Sao Paulo, 1973, 15, 30.

2 Brugmans, J. P., et al., fournal of the American Medical Association, 1971, $217,313$.

3 Chaia, G., and Sales da Cunha, A., Fôlha Medica, 1971, 63, 843.

4 Peña Chavarria, A., et al., American fournal of Tropical Medicine and Hygiene, 1973, 22, 592 .

5 Thompson, R. G., Hutchison, J. G. P., and Johnston, N. M., British Medical fournal, 1972, 1, 591 .

${ }^{6}$ Allen, A. V. H., and Ridley, D. S., Fournal of Clinical Pathology, 1970,

23, 545. 7 ., et al., British Medical fournal, 1972, 4, 73.
}

Third Department of Medicine, University of Helsinki, Finland PERTTI MUSTAJOKI, M.D., Research Fellow

Institute of Occupational Health, Helsinki, Finland ANNA MARIA SEPPÄLÄINEN, M.D., Neurophysiologist motor conduction velocity of the median, ulnar, deep peroneal, or posterior tibial nerves. Slight peripheral neuropathy seems to be associated with latent hereditary hepatic porphyria, even in patients who have never had symptoms.

\section{Introduction}

All the symptoms in the acute phase of hereditary hepatic porphyria are probably due to damage to the autonomic, peripheral, or central nervous system. ${ }^{1}$ In severe porphyria, neuropathy is a typical and well-known finding. Because of the intermittent character of hereditary hepatic porphyria, however, most patients are symptomless almost all their lives, showing only an increased excretion of porphyrins and their precursors. In lead poisoning, which resembles porphyria, ${ }^{2}$ disturbances in nerve conduction without clinical symptoms have been noted. ${ }^{3}$ The purpose of this study was to find whether similar changes occur in latent acute intermittent porphyria and latent variegate porphyria. 


\section{Materials and Methods}

Twenty patients with acute intermittent porphyria and five with variegate porphyria were studied, together with 25 controls matched for age and sex. The mean age of the patients was 35 years (range 13-60 years). Sixteen were female and nine male. None of the patients or controls suffered from diabetes, nephropathy, or alcoholism and none had been exposed to lead.

The patients were divided into two groups-(1) nine who had never had symptoms of porphyria, and (2) 16 who had had symptoms. Three of the 16 complained of recurrent non-specific pains or paraesthesia, and $13 \mathrm{had}$ had symptoms of acute porphyria one to 12 years earlierfour had had acute neurological symptoms, and nine acute abdominal symptoms. All but two of the patients had no symptoms or signs on examination, the remaining two showing slight neurological deficits after acute neurological episodes.

The diagnosis of 23 patients was based on increased levels of porphobilinogen in the urine or porphyrins in the faeces. Two patients had normal levels of porphobilinogen and porphyrin excretion. One, a 13-year-old girl from a porphyric family, was classified as a case of acute intermittent porphyria on the basis of clearly reduced uroporphyrinogen-I-synthetase activity in her red blood cells, and the other, whose uroporphyrinogen-I-synthetase activity was normal, was regarded as a case of acute intermittent porphyria on genetic grounds, his son and niece being verified cases.

Urinary porphyrin precursors were determined by the method of Mauzerall and Granick, ${ }^{4}$ and faecal porphyrins by that of Holti et al. ${ }^{5}$ Uroporphyrinogen-I-synthetase activity in red blood cells was measured by a modified version of the method of Strand et al. ${ }^{6}$ The maximum motor conduction velocity (M.C.V.) of the median, ulnar, deep peroneal, and posterior tibial nerves was measured. ${ }^{7}$ The conduction velocity of slower motor fibres (C.V.S.F.) of the ulnar nerve was determined on the basis of partial antidromic blocking. ${ }^{3}$ The nerves were stimulated with a Multistim apparatus (Disa) and a skin electrode. The responses were picked up with skin electrodes and amplified by an electromyograph (Disa). Sensory conduction velocity (S.C.V.) of the median and ulnar nerves was measured by stimulating the lateral aspects of the thumb and ring finger, respectively, with a skin electrode. Evoked nerve potentials were picked up with skin electrodes at the wrist and elbow, amplified by an electromyograph, and fed into a pulse analyser (Nokia Electronics), where 30 to 100 responses were averaged.

Electromyography of some arm and leg muscles was performed on nine patients with abnormal conduction velocities. All nerve studies were conducted in a warm laboratory $\left(25-26^{\circ} \mathrm{C}\right)$. The skin temperatures at the proximal stimulation points were always within normal limits $\left(30-34^{\circ} \mathrm{C}\right)$.

\section{Results}

The conduction velocities of the arm nerves were slower in the patients than in the controls (table I), the differences being significant for the C.V.S.F. of the ulnar nerve (see fig.) $(P<0.001)$ and the S.C.V.s of both the median and ulnar nerves $(P<0.05)$. Also, the distal latency of the median nerve was significantly longer in the patients (table II). Nerve conduction velocities were also analysed separately for groups 1 and 2. C.V.S.F. showed a similar distribution in both groups. Though the mean M.C.V.s and S.C.V.s were lower in group 2 the difference between the groups was not significant.

Electromyographical changes compatible with neuropathy were shown in eight of the nine patients studied. Five showed denervation potentials-namely, fibrillations-while the remaining three showed only neurogenic changes in the motor units or fasciculations. The only patient electromyographically normal was in group 1 .

TABLE I-Mean Nerve Conduction Velocities $(m / s)$ of 25 Patients with Latent Hereditary Hepatic Porphyria and 25 Controls. Results Expressed \pm S.D.

\begin{tabular}{|c|c|c|c|c|}
\hline & Patients & Controls & $t$ & $\mathbf{P}$ \\
\hline $\begin{array}{l}\text { M.C.V. of median nerve } \\
\text { S.C.V. of median nerve } \\
\text { M.C.V of ulnar nerve }\end{array}$ & $\begin{array}{l}56 \cdot 9 \pm 8 \cdot 8 \\
57 \cdot 5 \pm 6 \cdot 7 \\
58 \cdot 2 \pm 6 \cdot 5 \\
38 \cdot 2 \pm 4 \cdot 0 \\
55 \cdot 9 \pm 8 \cdot 1 \\
52 \cdot 1 \pm 5 \cdot 9 \\
49 \cdot 2 \pm 8 \cdot 9\end{array}$ & $\begin{array}{r}59 \cdot 9 \pm 4 \cdot 3 \\
61 \cdot 6 * 6^{*} \pm 4 \cdot 8 \\
59 \cdot 8 \pm 4 \cdot 2 \\
46 \cdot 3 \pm 4 \cdot 0 \\
60 \cdot 4 \pm 6 \cdot 1 \\
52 \cdot 1 \pm 3 \cdot 9 \\
47 \cdot 5 \pm 5 \cdot 4\end{array}$ & $\begin{array}{l}1.53 \\
2.06 \\
1.06 \\
7 \cdot 28 \\
2 \cdot 18 \\
0 \\
0 \cdot 80\end{array}$ & $\begin{array}{l}\text { N.S. } \\
<0.05 \\
\text { N.S. } \\
<0.001 \\
<0.05 \\
\text { N.S. } \\
\text { N.S. }\end{array}$ \\
\hline
\end{tabular}

* Only 11 controls in this series.

M.C.V. = Maximum motor conduction velocity. S.C.V.= Sensory conduction velocity. C.V.S.F.= Conduction velocity of slower motor fibres. N.S.=Not significant.
TABle II-Mean Motor Distal Latencies (ms) of Arm Nerves in 25 Patients with Latent Hereditary Hepatic Porphyria and 25 Controls. Results Expressed with Laten
\pm S.D.

\begin{tabular}{|c|c|c|c|c|c|c|}
\hline & & & Patients & Controls & $t$ & $\mathbf{P}$ \\
\hline $\begin{array}{l}\text { Median nerve .. } \\
\text { Ulnar nerve } \quad . .\end{array}$ & $\ldots$ & $\therefore$ & $\begin{array}{l}4 \cdot 28 \pm 1 \cdot 24 \\
3.65 \pm 0.59\end{array}$ & $\begin{array}{l}3 \cdot 77 \pm 0 \cdot 30 \\
3 \cdot 45 \pm 0 \cdot 26\end{array}$ & $\begin{array}{l}2.00 \\
1.55\end{array}$ & $\begin{array}{l}<0.05 \\
\text { N.S. }\end{array}$ \\
\hline
\end{tabular}

The findings showed no correlation with age, sex, type of porphyria, the excretion of porphyrin precursors or porphyrins, or the level of uroporphyrinogen-I-synthetase activity in the red blood cells.

\section{Discussion}

In this study neurophysiological abnormalities were found in symptomless porphyric patients. Abnormalities in the C.V.S.F. were evident also in porphyric patients who had never had symptoms. This suggests the existence of peripheral neuropathy in patients with hereditary hepatic porphyria who have never had acute attacks. In acute porphyria, even with neurological manifestations, M.C.V.s have been reported as mostly normal $^{8}{ }^{9}$ or rapidly reversible. ${ }^{10}$ M.C.V. is insensitive in detecting slight, especially axonal neuropathy. Neuropathy in latent porphyria is mild because the less sensitive M.C.V.s are mainly normal, and pathological values were noted in measurements known to be sensitive. S.C.V. is slowed earlier than M.C.V. also, for example, in diabetic and uraemic neuropathy, ${ }^{11}$ and a slowing of the C.V.S.F. together with a prolongation of the motor distal latency of the median nerve are strongly indicative of subclinical lead neuropathy. ${ }^{3}$

Porphobilinogen in "porphyric" concentrations causes in vitro inhibition at neuromuscular junctions. ${ }^{12}$ Possibly porphyrin precursors themselves are toxic and the cause of symptoms in acute porphyria. ${ }^{13} 14$ Our results do not support this view, since a slowed C.V.S.F. was also found in patients with only slightly raised or even normal porphobilinogen excretion.

The similarity of our findings with those of a study of subclinical lead poisoning ${ }^{3}$ are unlikely to be coincidental and illustrate the need to search for common mechanisms in these diseases.

We express our sincere thanks to Dr. Pentti Koskelo for his advice on the preparation of the manuscript. 


\section{References}

1 Goldberg, A., Quarterly fournal of Medicine, 1959, 28, 183.

2 Dagg, J. H., et al., Quarterly Fournal of Medicine, 1965, 34, 163

Seppalainen, A. M., and Hernberg, S., British fournal of Industrial Medicine, 1972, 29, 443.

4 Mauzerall, D., and Granick, S., fournal of Biological Chemistry, 1956, $219,435$.

5 Holti, G., et al., Quarterly fournal of Medicine, 1958, 27, 1.

- Strand, L. J., et al., Fournal of Clinical Investigation, 1972, 51, 2530.

7 Hodes, R., Larrabee, M. G., and German, W., Archives of Neurology and Psychiatry, 1948, 60, 340. ${ }^{8}$ Simpson, J. A., in Progress in Electromyography, ed. P. Pinelli, F.

${ }^{9}$ Maytham, D. V., and Eales, L., South African fournal of Laboratory and Clinical Medicine, 1971, 17, 99 .

10 Nagler, W., Annals of Internal Medicine, 1972, 76, 878.

11 Smorto, M. P., and Basmajian, J. V., Clinical Electroneurography. Baltimore, Williams and Wilkins, 1972.

12 Feldman, D. S., et al., Proceedings of the National Academy of Sciences, $1971,68,383$.

13 Kraemer, S., Becker, D., and Viljoen, D., South African Medical fournal, $1973,47,1735$.

14 Watson, C. J., et al., Annals of Internal Medicine, 1973, 79, 80.

\title{
Progressive Peripheral Neuropathy in Patient with Primary Hyperoxaluria
}

\author{
P. J. MOORHEAD， D. J. COOPER，W. R. TIMPERLEY
}

British Medical fournal, 1975, 2, 312-313

\section{Summary}

In a patient suffering from primary hyperoxaluria with oxalosis a progressive peripheral neuropathy was associated with intra-axonal deposition of microcrystals of calcium oxalate. Probably his neuropathy was the result of mechanical obstruction of axoplasmic flow.

\section{Introduction}

Primary hyperoxaluria is an autosomal recessive disorder in which the rate of formation of oxalate is up to three times greater than normal ${ }^{1}$ and calcium oxalate crystals become widely deposited throughout the body. ${ }^{2}{ }^{3}$ Variation in the density of deposition of oxalate depends partly on the availability of calcium ions in local tissue. ${ }^{4}$ Deposition of calcium oxalate crystals in nervous tissue has not been described in oxalosis. We describe here a case of primary hyperoxaluria in which peripheral neuropathy was a definite clinical and pathological feature.

\section{Case Report}

A 23-year-old man presented in April 1971 in advanced uraemia (glomerular filtration rate $5 \mathrm{ml} / \mathrm{min}$ ). He had passed hundreds of small renal stones, often with renal colic, for about 10 years, and an older sister had a similar history. A high-dose intravenous pyelogram showed much calcification at the corticomedullary junctions. His parathyroid glands had been explored three years earlier and were normal. He was normotensive, and his reflexes were normal.

His uraemia could not be controlled by conservative measures, and he was admitted to the chronic haemodialysis programme. Over the next six months of apparently adequate dialysis (predialysis serum creatinine $<884 \mu \mathrm{mol} / 1(10 \mathrm{mg} / 100 \mathrm{ml})$ ) his arm and leg tendon reflexes diminished and disappeared permanently. Nerve conduction studies showed gross slowing of conduction. Painful paraesthesiae and weakness of his legs prevented walking. Repeated episodes of ventricular arrhythmias occurred, and in January 1974 he suffered a cardiac arrest and died. He had taken $2 \mathrm{mg}$ pyridoxine daily throughout the entire period of intermittent dialysis.

Northern General Hospital, Sheffield S5 7AU

P. J. MOORHEAD, M.B., M.R.C.P., Consultant Renal Physician

D. J. COOPER, M.B., M.R.C.PATH., Senior Registrar in Pathology

Royal Infirmary, Sheffield S6 3DA

W. R. TIMPERLEY, D.M., M.R.C.PATH., Consultant Neuropathologist
NECROPSY

The heart weighed $525 \mathrm{~g}$; the ventricles were considerably thickened, and their cut surfaces were gritty. The kidneys were moderately atrophied, with numerous small $(1-3 \mathrm{~mm})$ stones in the calices and throughout the parenchyma. The retia testes had gritty cut surfaces.

Paraffin sections were stained with haematoxylin and eosin. Sections of psoas and gastrocnemius muscle were stained for lactate dehydrogenase, reduced diphosphopyridine nucleotide diaphorase, ${ }^{5}$ and myosin adenosine triphosphatase. ${ }^{6}$ Teased nerve preparations were made from sciatic and peroneal nerve, and were stained with $1 \%$ osmium tetroxide. ${ }^{7}$ Oxalate crystals were shown in sections using polarized light. They had the appearance of broken plates or of sheaves and rosettes of needles.

Heavy deposits of calcium oxalate crystals were seen throughout the renal parenchyma, the retia testes, the myocardium, and the media of the aorta and arterioles in all organs except the brain and meninges. Moderate deposits were present in the seminiferous tubules, thyroid, and voluntary muscle. Sparse deposits were present in the bronchial cartilage, bone marrow and trabeculae, parathyroids, pancreas, prostate, gastric submucosa, and choroid plexus. Sections of psoas and gastrocnemius muscle showed deposits within the endomysium which were surrounded by prominent foreign-body granulomata. The arterioles of these muscles contained deposits within the media and the intima; marked intimal proliferation had often occluded the lumen. Groups of muscle fibres showed typical neurogenic atrophy (fig. 1). Parts of the muscle showed ischaemic changes.

Teased nerve preparations of both sciatic and peroneal nerve showed deposits of calcium oxalate within the endoneurium. Single leaflets of crystals tended to lie in the longitudinal axis of nerve fibres (fig. 2) and many axons contained multiple crystals along their length.

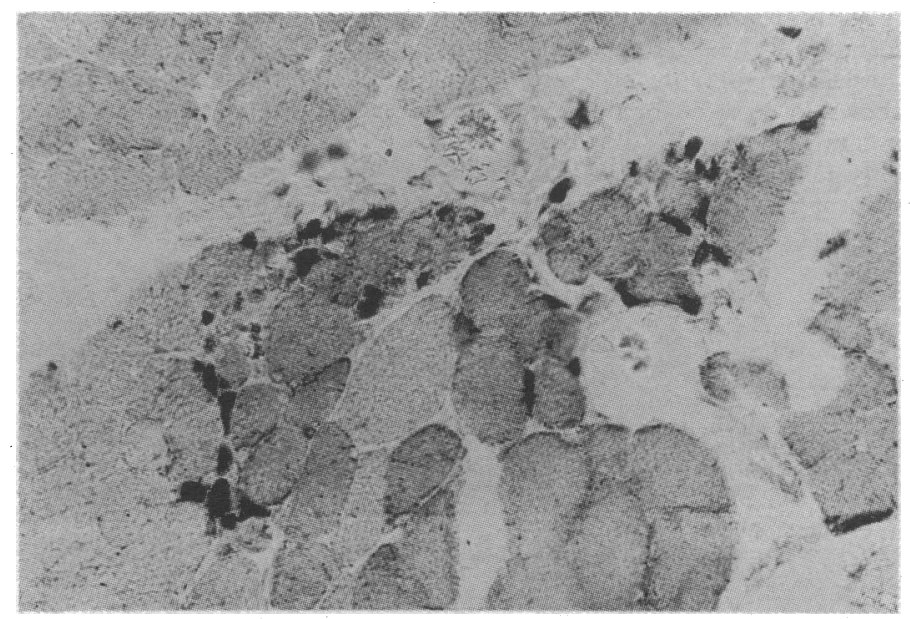

FIG. 1-Groups of atrophied fibres in psoas major muscle showing strong activity for lactic dehydrogenase. ( $\times 10$. 